\title{
GLOSSARY
}

\section{A glossary for research in occupational health}

\section{A M García, H Checkoway}

J Epidemiol Community Health 2003;57:7-10

This glossary includes a selection of terms pertaining to the field of research in occupational health. The glossary is mostly addressed to readers not familiarised with the more specific terms used in the study and protection of workers' health. The terms have been ordered according to their logical connections, so the glossary can be read from beginning to end giving the reader an overview on occupational health research main focuses, methods, and applications.

\section{OCCUPATIONAL EXPOSURES AND HEALTH EFFECTS \\ Occupational exposures}

Occupational exposures include physical conditions (for example, structural insecurity or deficient lighting), physical stress (for example, lifting heavy weights or repetitive strain injuries), physical agents (for example, noise, vibration, or radiation), chemicals (for example, dusts or solvents), biological agents (for example, bacteria or viruses), and psychosocial stressors (for example, low control over job tasks or poor communication with workmates, see Job strain model). Although many occupational exposures may occur as environmental exposures for the general population, workers are usually exposed to higher levels and are frequently the focus of research on health effects of these exposures and agents.

\section{Job strain model}

In the late 1970s Karasek formulated a model to explain work related stress based on two dimensions: job demands, mostly psychological conflicts related to work pace or workload, and job control (or job decision latitude), defined as the combination of the worker's job decision making authority and use of skills on the job. ${ }^{1}$ According to this model, jobs characterised by high "psychological workload demands" and low "decision latitude" increase risk for psychological job strain. Research on this area has consistently shown that increased decision latitude is preferable, rather than reduced job demand, in reducing mental strain. To measure the various components of the job strain model Karasek developed a questionnaire, the Job Content Questionnaire, which has been validated and frequently applied in the research of stress related to work and its effects on workers' behaviour and health. ${ }^{2}$ A third dimension was introduced in Karasek's model by Johnson and Hall, named the "work place social support", ${ }^{3}$ acting as an effect modifier over the other two dimensions and comprising social support at work given by workmates and by supervisors, foremen, and employers.

\section{Work related diseases}

Workplace exposures and conditions can act as component causes of a wide range of diseases. The classic text by physician and philosopher Bernardino Ramazzini (1633-1714), De morbis artificum diatriba, is considered the first comprehensive treatise on occupational disorders. ${ }^{4}$ Ramazzini recommended physicians to ask their patients, in addition to the classic Hippocratic questions, the nature of their occupation, a single point nowadays still too frequently disregarded. ${ }^{5}$ According to the criteria of a disease's frequency of occurrence, its severity in the individual case and its amenability to prevention, ${ }^{6}$ main work related diseases include occupational lung diseases, dermatological conditions, cardiovascular diseases, musculoskeletal injuries, disorders of reproduction and development, noise induced hearing loss, occupational cancer, neurological disorders, and psychological disorders. It has been estimated that the number of workers killed by diseases caused by occupational exposure greatly exceed the number who sustain fatal injuries ${ }^{7}$ (see Work related injuries), although the occupational causes of many diseases are frequently not recognised.

\section{Work related injuries}

Work related injuries are acute symptoms of deleterious workplace exposures. Occupational injuries have been defined as any damage inflicted to the body by energy transfer during work with a short duration between exposure and the health event, usually less than 48 hours. ${ }^{8}$ The term mostly refers to traumatic injuries, although conditions such as stroke are considered as occupational injuries in some worker's compensation schedules. Epidemiological research on occupational injuries has not been as much developed as for chronic diseases. ${ }^{9}$ Recently, some novel epidemiological designs have been applied to the analytical study of occupational injuries, ${ }^{10}$ such as the case-crossover studies (see below) in which both case and control information are taken from the same person.

\section{SOME SPECIFIC EPIDEMIOLOGICAL DESIGNS AND BIASES \\ Industry based studies}

Epidemiological industry based studies collect health and exposure information from a population of workers employed in a particular industry. ${ }^{11}$ In industry based studies accurate data on workplace exposures and exposure determinants are more easily available than for community based studies (see below).

\section{Community based studies}

Community based occupational studies are conducted in the population at large. ${ }^{11}$ Occupational 
exposure data are usually less detailed than in industry based studies because of the difficulties of collecting objective data from the variety of workplaces where study subjects worked. ${ }^{12}$ Hospital based case-control studies are representative of this approach. However, case-control studies can also be based on industrial populations, for example in case-crossover designs (see below) or nested case-control studies (see below).

\section{Nested case-control studies}

In occupational epidemiology, nested case-control studies usually refer to a case-control study nested within an occupational cohort already defined, enumerated, and followed up. The aim is to gain efficiency. Detailed information is only collected for incident cases generated in the cohort and a sample of workers without the condition of interest at the times when the cases arose. Individuals in the cohort should have had different levels of occupational exposure or different occupational exposures. As an example, this design was recently applied to the study of the relation between leukaemia and occupational exposures. ${ }^{13}$

\section{Case-crossover studies}

Case-crossover studies are an alternative to the traditional case-control studies in which both case and control information are taken from the same person. It has been described as a "self matched" case-control study. ${ }^{10}$ This design has been referred to as a "case only study" because only information on cases are required. Thus, each case serves as his or her own control. It was originally developed to evaluate the effect of transient exposures on the risk of an acute disease or injury triggering event, such as acute physical stress preceding a myocardial infarction. To date, there are only a few examples of this design applied to the study of occupational disorders, primarily acute injuries. An aetiologically relevant exposure window is defined before the event of interest and information about exposures acting during this window and other time periods should be gathered. As this information is obtained for the same subjects, some potential confounding factors (for example, psychological profile or job tasks) are unlikely to change appreciably over the observation period. There is a recent example of this approach applied to the study of transient risk factors for acute occupational traumatic hand injury demonstrating markedly increased risks associated with changed work conditions in the minutes or hours preceding the event. ${ }^{14}$

\section{Healthy worker effect}

Compared with the general population, workers have generally better health that permits employment. The healthy worker effect has been typically observed when mortality rates of employed population are compared with those in the general population, the workers' cohort showing lower mortality rates. ${ }^{15}$ It can also affect case-control and cross sectional studies involving sampling from an occupational cohort experience over the time and epidemiological designs focused on other health end points than death. ${ }^{11}$ The healthy worker effect can be considered as a selection bias in regards to the comparison group, or as a confounding consequence of the factor "previous health status", associated both to exposure and to subsequent health status. Potential causes and effects of the healthy worker effect should be properly evaluated in any occupational epidemiology study.

\section{Healthy worker survivor effect}

This effect refers to the selection process by which workers affected by their occupational exposure terminate prematurely their working life or transfer from higher to lesser exposed jobs, generally leading to under-estimation of risks and dose-response estimation. The healthy worker survivor effect is most prominent in cross sectional studies of disease prevalence and exposure. There have been proposed several approaches to control the healthy worker effect in epidemiological research of occupational exposures and health effects, including reconstructing the past onset times of disease incidence and relating exposures to incidence (rather than prevalence). ${ }^{16}$

\section{EXPOSURE RELATED ISSUES}

\section{Exposure assessment}

Exposure assessment in occupational research is the estimation of workers' exposures. Accurate exposure assessment is a challenge in almost every observational study. ${ }^{17}$ During the past years the methods for occupational exposure assessment have greatly developed, including approaches based on modelling of occupational hygiene data, expert's exposure ratings, or specific questionnaires. Biological markers may also provide valuable information for occupational exposure assessment (see Biological monitoring). This progress has become more crucial as many of the major occupational risk factors are now identified, but proper knowledge is still needed on the effects of low level exposures present in complex workplace environments.

\section{Occupational environmental monitoring}

Occupational environmental monitoring is intended to gather information on occupational exposures (see above) in the environment external to the worker through direct measurements. Intensity and duration of exposure can be measured. For chemicals the term concentration is also used to refer to the amount of the substance per unit of environmental medium (for example, micrograms of lead per cubic metre of air). ${ }^{11}$ Strategies for environmental monitoring are usually based on grouping procedures (that is, applying a sampling strategy intended to describe environmental exposures of a group of workers with similar tasks, using similar agents and/or working under similar conditions). Area measurements (such as through air samplers) or personal measurements (through personal dosimeters) can be conducted. A proper strategy to identify and measure variations of intensity of exposure in time should also be considered.

\section{Biological monitoring}

Biological monitoring is the measurement in the workers' body of biological markers (biomarkers) related to occupational exposures. Exposure biomarkers are concentrations of exposure substances in human tissues, cells, or fluids. Examples are blood lead concentrations, pesticide metabolites in urine, and solvent concentrations in exhaled breath. Other biomarkers may be defined as biochemical alterations or responses to exposures, or indicators of host susceptibility. ${ }^{18}$ Workers exposed to certain chemical agents (for example, lead) should undergo routinary biological monitoring to measure the levels of the original substance, their metabolites or related measurable changes in biological samples. Limit values for these levels have been established and are contemplated in occupational health legislation of many countries. Biological indices of exposure (BIEs), regularly published by the American Conference of Governmental Industrial Hygienists (ACGIH) besides threshold limit values (see below), ${ }^{19}$ are an example. Systematic information from biological monitoring of workers populations can be used for occupational epidemiology research. However, although the use of biomarkers has opened a new promising field for epidemiology, constraints of this approach should be noticed. ${ }^{18}{ }^{20}$ Knowledge on biomarker distributions in general populations and on inter-individual and intra-individual variability is often limited. On the other hand, for many exposures there are not available valid or applicable biomarkers. 


\section{Occupational history}

In retrospective occupational epidemiological studies it is crucial to collect accurate occupational histories of individuals in the study to properly assess occupational exposures of interest. ${ }^{112} 1721$ Ocupational history data are usually obtained from personnel records in industry based studies, or may be obtained from questionnaires in community based studies. Important items to be considered in occupational histories include industry or type of business, company name and location, dates of employment, job titles and associated dates started and stopped, tasks or activities developed, and equipments and materials used. In some situations information can also be gathered regarding specific working conditions that can act as exposure determinants (for exampe, use of personal protection or other occupational health and safety determinants). Population based registries, such as cancer or congenital malformations registries, and routinely collected vital records, such as death or birth certificates, sometimes include some information on occupational history. The degree of detail and accuracy of this information can greatly vary, however.

\section{Job exposure matrices}

A job exposure matrix (JEM) may be defined as a cross classification of jobs and occupational exposures. Some matrices are based on tasks, instead of jobs. In 1980, Hoar et al ${ }^{22}$ first proposed a systematic approach to JEMs for epidemiological research and since then the method has been widely applied. Several improvements have been attained. ${ }^{23}$ Usually there is a group of experts who build the matrix based on their own knowledge and experience on occupational exposures. The experts should assess exposure to an open or fixed list of occupational exposures (that can include chemical, physical, biological and/or psychosocial agents) for an open or fixed list of jobs (or tasks) usually coded according to some established national or international classification system. Some JEMs also include information for different calendar time periods.

\section{Experts' assessment of exposure}

The process of experts' assessment of exposure shares common features to that applied for devising JEMs. Siemiatycki et al first applied this approach to a large hospital based case-control study of occupational risk factors for numerous cancer types. ${ }^{24}$ In its more common form, the experts assess presence, level, and probability of exposure to an open or fixed list of agents according to information gathered in the occupational history of each person in the study. Expert assessment is most useful in situations where direct exposure measurements are not available, such as in community based studies that rely on questionnaire information. Although this approach has been considered among the more accurate strategies for retrospective assessment of exposure in occupational epidemiology research, few attempts at validation have been made to illuminate the black box of the exposure assessor. $^{25}$

\section{OCCUPATIONAL EXPOSURE AND HEALTH SURVEILLANCE \\ Risk assessment}

Regulation of occupational or environmental limits for health damaging exposures is based on the process of risk assessment. ${ }^{26}$ Steps in risk assessment for a given exposure include: (1) hazard identification, or the evaluation of evidence on negative effects on human health from the exposure; (2) exposure assessment, or determination of the specific agents, routes, amount and duration of exposure causing human damage; (3) dose-response estimation, to extrapolate available evidence on the relation between dose and adverse health response to human conditions of exposure; and (4) risk characterisation, combining exposure assessment with doseresponse assessment to quantify the risks from a given expo- sure to human populations. From some occupational epidemiology studies, usually cohort studies, dose-response relations can be derived and used to set regulatory standards, although most epidemiological research can only contribute to occupational hazard identification or to explore the plausibility of resumed exposure/disease associations (for example, from animal experiments).

\section{Threshold limit value (TLV)}

The American Conference of Governmental Industrial Hygienists (ACGIH) publish regularly an unofficial guide of acceptable limits for exposure to chemical and physical agents in the workplace. ${ }^{19}$ TLVs are exposure limits included in this guide and express mean or peak concentrations over a given period that an environmental pollutant must not exceed. The ACGIH defines TLVs for chemical substances as "airborne concentrations of substances representing conditions under which it is believed that nearly all workers may be repeatedly exposed day after day without adverse effect". However, experience over time and critical review of the documentation supporting the TLVs have shown a poor correlation between these limits and incidence of adverse health effects in exposed workers. Some researchers have pointed out that TLVs are a compromise between health based considerations and strictly practical industrial considerations. ${ }^{27}$ Despite this, TLVs have been and are widely applied by many countries as the only reference to protect workers' health from deleterious exposures at work. During the past years the European Union has been working to develop its own harmonised set of occupational exposure limits (OELs). ${ }^{28}$

\section{Occupational sentinel health events}

In 1983 Rutstein et $a l^{29}$ defined the sentinel health event (occupational) $(\mathrm{SEH}(\mathrm{O}))$ as an unnecessary disease, disability or ultimately death that is occupationally related, and whose occurrence may provide the impetus for epidemiological or industrial hygiene studies or serve as a warning signal that materials substitution, engineering control, personal protection, or medical care may be required. Based on occupational health literature revision these authors elaborated a list with two broad categories of $\operatorname{SHE}(\mathrm{O})$ : diseases unlikely to occur in the absence of an occupational exposure (such as pneumoconiosis), and diseases that may or may not be occupationally related (such as lung cancer). Fifty conditions were included in this list, coded according to ICD-9 classification and with information on their potential for proper prevention and/or treatment and on the industries or occupations where exposure to the causal agent may occur. One illustrative example is malignant mesothelioma, which is considered to be caused almost exclusively by occupational asbestos exposure. As stated by the authors, the list provided an insight into priority setting for occupational health researchers. The original list was revised by Mullan and Murthy in 1991, ${ }^{30}$ updating and adding information on all the fields and finally comprising 64 disease conditions.

\section{Authors' affiliations}

A M García, Department of Preventive Medicine and Public Health, University of Valencia, Spain

H Checkoway, Department of Environmental Health, University of Washington, Seattle, USA

\section{REFERENCES}

1 Karasek RA. Job demands, job decision latitude and mental strain: implications for job re-design. Administr Sci Q 1979:24:285-308.

2 Karasek RA, Theorrell T. Healthy work: stress, productivity and the reconstruction of working life. New York: Basic Books, 1990.

3 Johnson JV, Hall E. Job strain, work place social support and cardiovascular disease: a prospective study of Swedish men. Am J Public Health 1988;78:1336-42.

4 Franco G. Ramazzini and workers' health. Lancet 1999;354:858-61. 
5 Rosenstock L. Occupational medicine: too long neglected. Ann Intern Med 1981;95:774-6.

6 Centers for Disease Control and Prevention. Leading work-related diseased and injuries-United Stated. MMWR 1985;34:24-6.

7 Herbert $\mathbf{R}$, Landrigan PJ. Work-related death: a continuing epidemic. Am J Public Health 2000;90:541-5.

8 Hagberg M, Christiani D, Courtney TK, et al. Conceptual and definitional issues in occupational injury methodology. Am J Ind Med 1997;32:106-15.

9 Veazie MA, Landen DD, Bender TR, et al. Epidemiologic research on the etiology of injuries at work. Ann Rev Public Health 1994;15:203-21.

10 Mittleman MA, Maldonado G, Gerberich SG, et al. Alternative approaches to analytical designs in occupational injury epidemiology Am J Ind Med 1997;32:129-41.

11 Checkoway H, Pearce NE, Crawford-Brown DJ. Research methods in occupational epidemiology. New York: Oxford University Press, 1989

12 Stewart WF, Stewart PA. Occupational case-control studies: I. Collecting information on work histories and work-related exposures. Am J Ind Med 1994;26:297-312.

13 Guenel P, Imbernon E, Chevalier A, et al. Leukemia in relation to occupational exposures to benzene and other agents: a case-control study nested in a cohort of gas and electric utility workers. Am J Ind Med 2002;42:87-97.

14 Sorock GS, Lombardi DA, Hauser RB, et al. A case-crossover study of occupational traumatic hand injury: methods and initial findings. Am J Ind Med 2001;39:171-9.

15 Fox AJ, Collier PF. Low mortality raters in industrial cohort studies due to selection for work and survival in the industry. Br J Prev Soc Med 1976;30:225-30

16 Arrighi HM, Hertz-Picciotto I. The evolving concept of the healthy worker survivor effect. Epidemiology 1994;5:189-96.

17 Armstrong BK, White E, Saracci R. Principles of exposure measurement on epidemiology. Oxford: Oxford University Press, 1992

18 Hulka BS, Wilcosky TC, Griffith JD. Biological markers in epidemiology. Oxford: Oxford University Press, 1990.
19 American Conference of Governmental Industrial Hygienists. Home page. http://www.acgih.org/home.htm (consulted 23 July 2002).

20 Pearce N, de Sanjosé S, Boffetta $P$, et al. Limitations of biomarkers of exposure in cancer epidemiology. Epidemiology 1995;6:190-4.

21 Stewart PA, Stewart WF. Occupational case-control studies: II. Recommendations for exposure assessment. Am J Ind Med 1994;26:313-26.

22 Hoar SK, Morrison AS, Cole P, et al. An occupation and exposure linkage system for the study of occupational carcinogenesis. J Occup Med 1980;22:722-5.

23 Kauppinen T, Toikkanen J, Pukkala E. From cross-tabulation to multipurpose exposure information systems: a new job-exposure matrix. Am J Ind Med 1998;33:409-17.

24 Siemiatycki J, Nadon L, Lakhani R, et al. Exposure assessment. In: Siemiatycki J, ed. Risk factors for cancer in the workplace. Boca Raton: CRC Press, 1991:45-114.

25 Kauppinen T. Exposure assessment-a challenge for occupational epidemiology. Scand J Work Environ Health 1996;22:401-3.

26 Hertz-Picciotto I. Epidemiology and quantitative risk assessment: a bridge from science to policy. Am J Public Health 19995;85:484-91.

27 Roach SA, Rappaport SM. But they are not thresholds: a critical analysis of the documentation of threshold limit values. Am J Ind Med 1990; 17:727-53.

28 European Agency for Safety and Health at Work. Occupational Exposure Limits. Available at: http://europe.osha.eu.int/good practice/ risks/ds/oel/ (consulted 23 July 2002).

29 Rutstein DD, Mullan RJ, Frazier TM, et al. Sentinel health events (occupational): a basis for physician recognition and public health surveillance. Am J Public Health 1983;73:1054-62.

30 Mullan RJ, Murthy LI. Occupational sentinel health events: an up-dated list for physician recognition and public health surveillance. Am J Ind Med 1991;19:775-99. 